\title{
Numerical Well Test for Well with Finite Conductivity Vertical Frac- ture in Coalbed
}

\author{
Y. W. Liu ${ }^{1, *}$, W. P. Ouyang ${ }^{1}$, P. H. Zhao ${ }^{2}$, Q. Lu ${ }^{2}$, H. J. Fang ${ }^{3}$ \\ ${ }^{1}$ Key Laboratory of Environment Mechanics, Institute of Mechanics, Chinese Academy of Sciences, Beijing 100190, \\ China \\ ${ }^{2}$ Coalbed Methane Ltd. Company, Petrochina, Beijing 100028, China \\ ${ }^{3}$ Well Test Department of Geermu Oil Factor of Qinghai Oil Field, Qinghai 816000, China
}

Email: lywu@imech.ac.cn

\begin{abstract}
A new model is developed for the hydraulic fractured well in coalbed, by considering the following aspects: methane desorption phenomena, finite conductivity vertical fracture, and asymmetry of the fracture about the well. A new parameter is introduced to describe the storage of the fracture, which is named combined fracture storage. Another new concept called fracture asymmetry coefficient is used to define the asymmetry of the fracture about the well. FEM is used to solve the new mathematic model. Both well test type curve and seepage field are got and analyzed. The effects of combined fracture storage, desorption factor, the fracture conductivity, fracture asymmetry coefficient, etc. on type curve are all discussed in detail in this paper.
\end{abstract}

Key words: coalbed, fractured well, numerical method, FEM, finite conductivity

\section{INTRODUCTION}

Coalbed methane is one of the most important gas resources developed recently in China. To study well test method in coalbed, especially how to assess the fractured wells are a key step for reasonable producing process. Only a few numerical models are presented on the hydraulic fractured well in domestic and abroad. Gringarten et al. [1] developed a model of uniform flex and infinite conductivity for vertical fractured well in normal reservoir. Cinco-Lee et al. [2] introduced well test model for the fractured well with finite conductivity fracture firstly. He et al. [3] found a model to assess new finite conductivity fractured well by considering the deformation of media in CBM. In 2005, Y.W. Liu et al. [4] developed the numerical model for the multiwells in coalbed at first time. These research all used the Langmuir adsorption theory. In 2010, Ouyang et al. [5] developed a new model for fractured well with infinite conductivity fracture. On basis of above, a new numerical model for fractured well with finite conductivity vertical fracture is presented in this paper.

\section{MATHEMATICAL MODEL}

Governing equation

$\frac{\partial^{2} p_{\mathrm{D}}}{\partial x_{\mathrm{D}}^{2}}+\frac{\partial^{2} p_{\mathrm{D}}}{\partial y_{\mathrm{D}}^{2}}+\alpha_{1 \mathrm{D}}+\alpha_{2 \mathrm{D}}\left(p_{\mathrm{D}}-p_{\mathrm{CD}}\right)=\frac{1}{K_{\mathrm{r}} C_{\mathrm{D} f}} \frac{\partial p_{\mathrm{D}}}{\partial T_{\mathrm{D}}}, \quad x_{\mathrm{D}}, y_{\mathrm{D}} \in \Omega$

Initialcondition : $\quad p_{\mathrm{D}}=0$

Innerboundarycondition : $\left.\sum L_{i \mathrm{D}}\left(\frac{\partial p_{i \mathrm{D}}}{\partial n}\right)\right|_{\Gamma_{\mathrm{in}}}=2 \pi\left(-1+\frac{\mathrm{d} p_{w \mathrm{D}}}{\mathrm{d} T_{\mathrm{D}}}\right)$

Outer boundary condition 
Infiniteboundary : $\left.\quad p_{\mathrm{D}}\right|_{x, y \rightarrow \infty}=0$

Constantpressureboundary : $\left.p_{\mathrm{D}}\right|_{\Gamma_{\mathrm{out}}}=0$

Closedboundary : $\left.\frac{\partial p_{\mathrm{D}}}{\partial n}\right|_{\Gamma_{\text {out }}}=0$

Where: $p_{\mathrm{D}}$ is the dimensionless pressure, $T_{\mathrm{D}}$ is the dimensionless time, $x_{\mathrm{D}}, y_{\mathrm{D}}$ is the dimensionless position in the coalbed, $p_{\mathrm{CD}}$ is the dimensionless critical adsorption pressure, $\alpha_{1 \mathrm{D}}$ is the dimensionless steady adsorption coefficient, $\alpha_{2 \mathrm{D}}$ is the dimensionless unsteady adsorption coefficient, $L_{i \mathrm{D}}$ is the dimensionless length of fracture, $\Gamma_{\mathrm{in}}$ indicates the inner boundary, $\Gamma_{\text {out }}$ indicates the outer boundary, $\Omega$ indicates the research region, $C_{f \mathrm{D}}$ is the dimensionless combined fracture storage, $K_{\mathrm{r}}$ is the ratio of permeabilities between the fracture and the coalbed.

\section{CALCULATING METHOD}

1. FEM method To solve the above mathematical model, Galerkin finite element method with weighted residual method and selected interpolation function $N_{i}$ as weight function is used, $N_{i}=a_{i}+b_{i} x+c_{i} y, i=1,2,3$. Then

$\iint_{A} N_{i}^{e}\left(\frac{\partial^{2} p_{\mathrm{D}}}{\partial x_{\mathrm{D}}^{2}}+\frac{\partial^{2} p_{\mathrm{D}}}{\partial y_{\mathrm{D}}^{2}}+\alpha_{1 \mathrm{D}}+\alpha_{2 \mathrm{D}} p_{\mathrm{D}}-\frac{1}{C_{\mathrm{D} f} K_{\mathrm{r}}} \frac{\partial p_{\mathrm{D}}}{\partial T_{\mathrm{D}}}\right) \mathrm{d} A=0$

The weak solution formation

$\iint_{A}\left(\frac{\partial N_{i}^{e}}{\partial x_{\mathrm{D}}} \frac{\partial p_{\mathrm{D}}}{\partial x_{\mathrm{D}}}+\frac{\partial N_{i}^{e}}{\partial y_{\mathrm{D}}} \frac{\partial p_{\mathrm{D}}}{\partial y_{\mathrm{D}}}-N_{i}^{e}\left(\alpha_{1 \mathrm{D}}+\alpha_{2 \mathrm{D}} p_{\mathrm{D}}\right)+\frac{N_{i}^{e}}{C_{\mathrm{D} f} K_{\mathrm{r}}} \frac{\partial p_{\mathrm{D}}}{\partial T_{\mathrm{D}}}\right) \mathrm{d} A=\int_{\Gamma} N_{i}^{e} \frac{\partial p_{w \mathrm{D}}}{\partial n} \mathrm{~d} l$

Finite element equations discretized

$$
\begin{aligned}
& K_{\mathrm{r}}\left(b_{i}^{2}+c_{i}^{2}+\frac{1}{6 C_{\mathrm{D} f} \Delta T_{\mathrm{D}}}-\frac{\alpha_{2 \mathrm{D}}}{6}\right) p_{i}^{e, n+1}+K_{\mathrm{r}}\left(b_{i} b_{j}+c_{i} c_{j}+\frac{1}{12 C_{\mathrm{D} f} \Delta T_{\mathrm{D}}}-\frac{\alpha_{2 \mathrm{D}}}{12}\right) p_{j}^{e, n+1}+ \\
& K_{\mathrm{r}}\left(b_{i} b_{k}+c_{i} c_{k}+\frac{1}{12 C_{\mathrm{D} f} \Delta T_{\mathrm{D}}}-\frac{\alpha_{2 \mathrm{D}}}{12}\right) p_{k}^{e, n+1}-\frac{L}{3} \frac{\partial p_{i}^{e, n+1}}{\partial n}-\frac{L}{6} \frac{\partial p_{j / k}^{e, n+1}}{\partial n}= \\
& \quad \frac{1}{6 C_{\mathrm{D} f} \Delta T_{\mathrm{D}}} p_{i}^{e, n}+\frac{1}{12 C_{\mathrm{D} f} \Delta T_{\mathrm{D}}} p_{j}^{e, n}+\frac{1}{12 C_{\mathrm{D} f} \Delta T_{\mathrm{D}}} p_{k}^{e, n}+\frac{\alpha_{1 \mathrm{D}} K_{\mathrm{r}}}{3}
\end{aligned}
$$

2. Discrete of grid for finite elements In order to calculate finite elements it is necessary to discrete the zone of object, using triangle grid under non-structural and with round out-boundary.

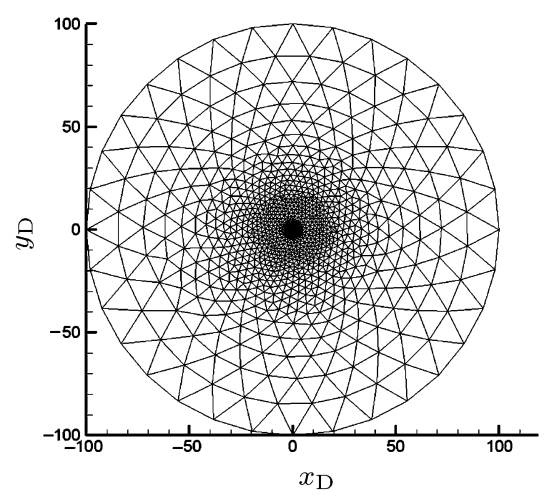

(a) Coalbed is round

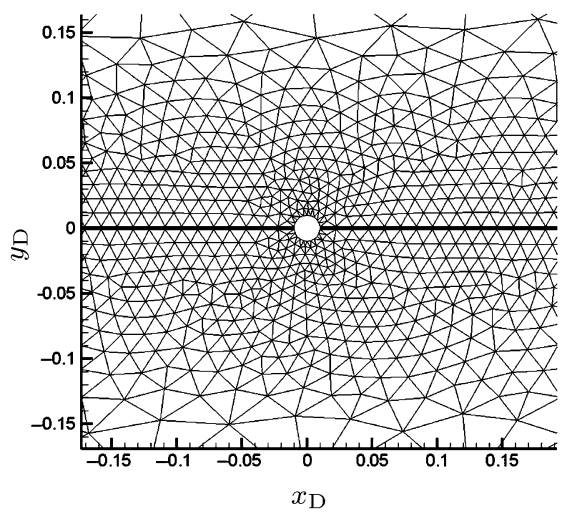

(b) A grid chart near well

Figure 1: Grid chart of coalbed with non-structure

\section{RESULT AND ANALYSIS}

1. Well test type curve The following parameters are taken: dimensionless fracture storage $C_{\mathrm{D} f}=0.001$, dimension -less fracture conductivity is 2, dimensionless fracture width is 0.002 and the radius of closed out boundary is 100 . The 
result of calculation is shown in Figure 2. It is generally divided 4 parts based on the characteristic curve of theory: the first part is wellboe control section line with slope 1, the second part indicated the finite conductivity fracture feature is the straight line with slope 0.25 . The third part is a horizontal line of 0.5 with radial fluid flow around the wellbore. The forth one is straight line with slope 1 shown the effect of boundary.

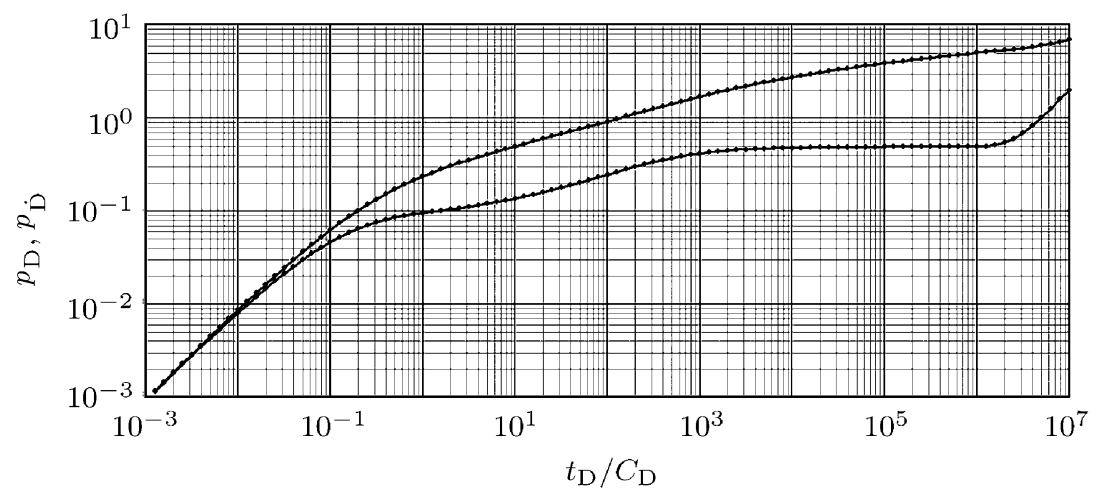

Figure 2: Log-Log type curve for fracture fractured well with finite conductivity fracture

2. Effects of desorption on type curves Considering the effect of stable desorption coefficient, i.e. $\alpha_{1 \mathrm{D}}$ of coalbed, we take $\alpha_{1 \mathrm{D}}=0,-10^{-4},-2.04 \times 10^{-4}$ respectively, and unstable desorption coefficient $\alpha_{2 \mathrm{D}}=0$, combined fracture storage $C_{\mathrm{D} f}=0.001$, the radius of boundary $R=100$. The results are shown in Figure 3 .

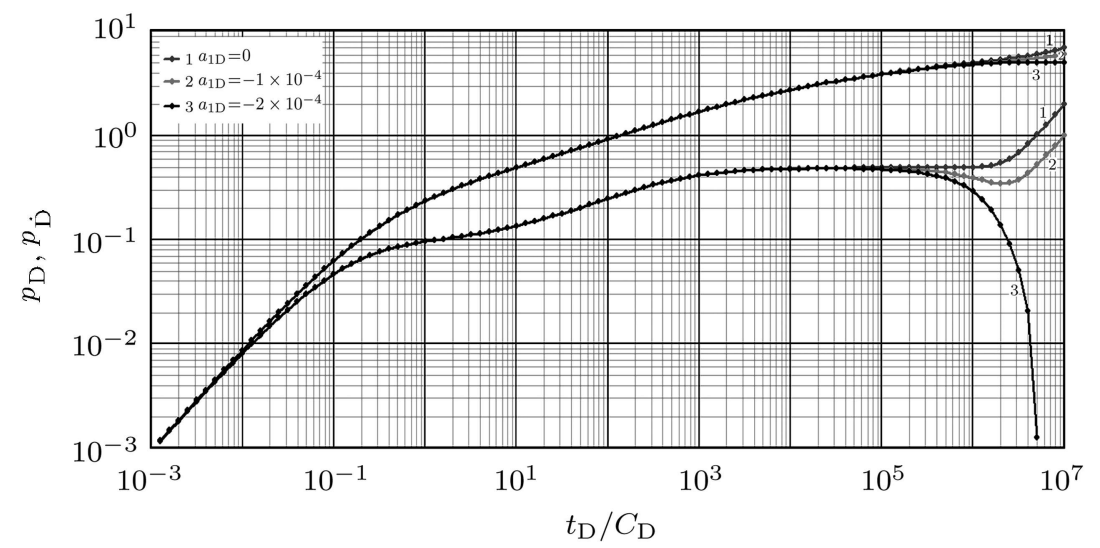

Figure 3: Log-Log type curves for fracture fractured well with different stable desorption coefficients

3. Seepage field The seepage fields for the fractured well with different fracture asymmetry coefficients are calculated. In order to see the pressure distribution near the fracture, the seepage fields near the fractured well are drawed as Figure 4. From Figure 4, it shows clearly that the fracture asymmetry coefficients have significant effects on the seepage fields.

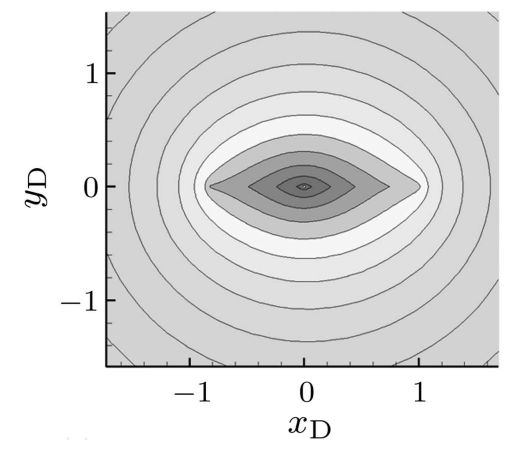

(a) Fracture asymmetry coefficient $2: 3$

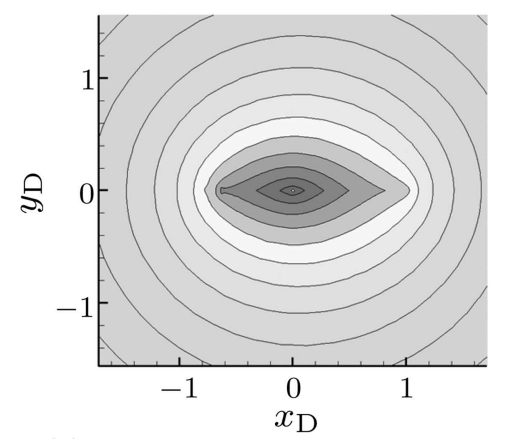

(b) Fracture asymmetry coefficient 3:7

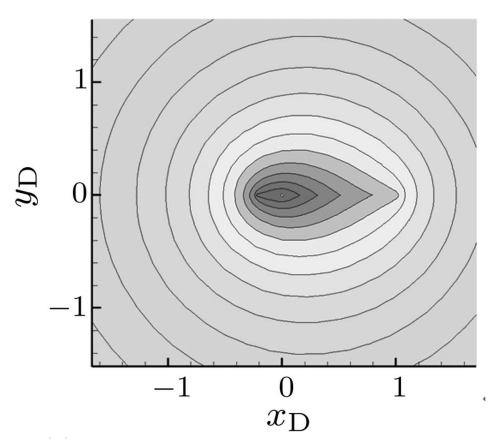

(c) Fracture asymmetry coefficient 1:9

Figure 4: Seepage fields near the fractured well with different fracture asymmetry coefficients

\section{CONCLUSSION}

(1) A new model is developed for the hydraulic fractured well in coalbed. Two new conceptions are introduced as combined fracture storage and fracture asymmetry coefficient. 
(2) The effects of methane desorption phenomena, finite conductivity vertical fracture, and asymmetry of the fracture about the well on well test type curves are discussed in detail.

(3) The results show that the desorption coefficient delays the pressure propagating in coalbed, the more higher the fracture conductivity, the more larger the drainage area. The fracture asymmetry about the well affects on the seepage field significantly.

\section{Acknowledgements}

The support of the National S\&T Major Project of China (2009ZX05038001) is gratefully acknowledged.

\section{REFERENCES}

1. Gringarten AC, Ramey Jr, et al, Unsteady-state pressure distributions created by a well with a single infiniteconductivity vertical fracture. presentated at the 47th Annual Fall Meeting of Socity of Petroleum of AIME, San Antanio, Tex., Oct. 8-11, 1972

2. Cinco-Ley H, Meng HZ. Pressure transient analysis of wells with finite conductivity vertical Fractures in double porosity reservoirs. The 63rd Annual Technical Conference and Exhibition of the Society of Petroleum Engineers, Houston, TX, October 2-5, 1988

3. He YF, Hang YP. Transient pressure analysis for fractured well in coalbed, Acta of Oil and Gas, 2006; 28(5): $113-117$

4. Liu YW, Zhang DW, et al. Numerical study on coalbed methane transient seepage flow with multiwells. Chinese Journal of Rock Mechanics and Engineering, 2005; 24(10): 1679-1685

5. Ouyang WP, Liu YW. Numerical well test model for CBM infinite conductivity vertical fracture well. Well Testing, 2010; 19(6): 53-56 